\title{
Collagenase production by rheumatoid synovial cells: morphological and immunohistochemical studies of the dendritic cell
}

\author{
DAVID E. WOOLLEY ${ }^{1}$, CONSTANCE E. BRINCKERHOFF, \\ CARLO L. MAINARDI, CAROL A. VATER, JOHN M. EVANSON ${ }^{1}$, \\ AND EDWARD D. HARRIS, JR.
}

From the Department of Medicine, Dartmouth-Hitchcock Medical Center, Hanover, New Hampshire 03755 , USA and the ${ }^{1}$ University Department of Medicine, University Hospital of South Manchester, West Didsbury Manchester M20 8LR, England

SUMMARY The dendritic cells of dissociated, adherent rheumatoid synovial cell cultures are recog= nised by their distinctive morphological features - compact cytoplasm around the nucleus and long branched cytoplasmic extensions. Such cells usually composed approximately $10 \%$ of the tota adherent cell population but could vary from as few as $2 \%$ to as many as $40 \%$ with different synoviato specimens. Histological studies have shown the cells to contain many mitochondria and large spherical cytoplasmic inclusions which often distort the dendritic extensions. Although lysosomes were observed, no evidence for phagocytic activity was obtained. Immunolocalisation studies bo means of a monospecific antibody to human collagenase have shown that the dendritic cell attacheo to a collagenous substratum produces and releases this enzyme in vitro. In contrast collagenase wa\$ detected in only a few of the fibroblast- and macrophage-like cells, and it was always intracellular. It i proposed that the dendritic cell may have an important role in the pathophysiology of the rheu $\overrightarrow{\bar{O}}$ matoid joint, particularly with regard to collagenase-mediated cartilage destruction.

The ability of rheumatoid synovial collagenase to degrade cartilage collagen and insoluble tissue collagens (Harris and McCroskery, 1974; Woolley et al., 1975a, 1975b), and the recent immunolocalisation of this enzyme at the cartilage-pannus junction of rheumatoid joints (Woolley et al., 1977) support the view that collagenase plays an important role in the pathophysiology of the rheumatoid joint. The collagenase used in most studies to date has been obtained from the serum-free culture medium (Evanson et al., 1968) of rheumatoid synovial tissue explants. However, Dayer et al. (1976) recently reported that monolayer cultures of dissociated, adherent rheumatoid synovial cells released relatively large quantities of enzyme and prostaglandins. Such cultures also revealed an unusual cell type, described as 'stellate' (Dayer et al., 1976) or 'dendritic' (Werb et al., 1977) which was characterised

\section{Accepted for publication 2 June, 1978}

Correspondence to Dr D. E. Woolley, University Department of Medicine, University Hospital of South Manchester, West Didsbury, Manchester M20 8LR. morphologically by its long, branched cytoplasmia extensions.

The 'stellate' cells were originally recognised in relatively long-term cultures (3-25 weeks) which contained fetal calf serum, and the observation was made that collagenase production might be related to the presence of these cells (Dayer et al., 1976). As other adherent cell types, for example, macrophages either disappeared or lost certain properties in suche long-term cultures we have examined short-terns cultures (up to 5 days) of adherent rheumatoid synovial cells in which serum was replaced by lactalbumin hydrolysate after the first $24 \mathrm{~h}$ (Werbw et al., 1977). This culture system, with its full com? plement of adherent rheumatoid synovial cells of varying morphology, allowed us to examine whicli cells were responsible for collagenase production:We report here on the various adherent cell types observed in serum-free cultures and describe ou collagenase immunolocalisation studies which implis cate the dendritic cell with its unusual morphology as that largely responsible for collagenase production in vitro. 


\section{Materials and methods}

RHEUMATOID SYNOVIAL CELL CULTURES

Fresh rheumatoid synovium obtained at time of synovectomy was minced and dissociated by enzymatic digestion as described by Dayer et al. (1976). Cells were plated on to glass coverslips $(22 \times 22 \mathrm{~mm})$ in plastic culture wells $32 \mathrm{~mm}$ in diameter (Costar 6-well cluster dishes, Microbiological Associates) at a concentration of $2.5 \times 10^{5}$ cells per well in Dulbecco's modified Eagle's medium (DMEM), $10 \%$ fetal calf serum, penicillin/streptomycin and L-glutamine added (Werb et al., 1977). After $24 \mathrm{~h}$ at $37^{\circ} \mathrm{C}$ in an atmosphere of $5 \% \mathrm{CO}_{2}$ in air the culture medium was changed. The cultures were washed 5 times with Hank's buffered salt solution (HBSS), thereby removing dead and non-adherent cells, and finally replenished with $2 \mathrm{ml}$ DMEM supplemented with $0.2 \%$ lactalbumin hydrolysate in place of serum. This culture medium was replaced every 24 or $48 \mathrm{~h}$ and cultures were usually maintained for up to 8 days.

For immunofluorescent and scanning electron microscope studies the cells were plated on to collagen-coated coverslips prepared by adding $1.5 \mathrm{ml}$ of a collagen solution (equivalent to $1 \mathrm{mg}$ collagen in $0.12 \mathrm{M} \mathrm{NaCl}$ and $0.02 \%$ sodium azide) to coverslips in each well and incubating at $37^{\circ} \mathrm{C}$. The thermally reconstituted collagen gels were then allowed to dry and washed 5 times with HBSS prior to use. For histological and enzymatic studies the cells were plated out and treated in the same way on glass coverslips without collagen.

\section{PHASE-CONTRAST MICROSCOPY}

Examination of the adherent rheumatoid synovial cells by phase contrast microscopy was performed on coverslips fixed for $5 \mathrm{~min}$ at room temperature in $1.5 \%$ glutaraldehyde (Fisher Chemicals) buffered with $0 \cdot 1 \mathrm{M}$ sodium cacodylate, $\mathrm{pH} 7 \cdot 5$. A Zeiss Photomicroscope III was used, and photographs were made using either Kodak Plus-X or High Speed Ektachrome films.

\section{STAINING PROCEDURES}

$\therefore$ ainus green and acridine orange at concentrations of $1 \mu \mathrm{g} / \mathrm{ml}$ DMEM were added to the cell cultures for $2 \mathrm{~min}$ at room temperature fcr the vital staining of r.uitochondria and lysosomes, respectively. For nucleic acid staining, glutaraldehyde-fixed cells were stained with $0.1 \%$ toluidine blue in $0.1 \mathrm{M}$ phosphate buffer ( $\mathrm{pH} 6 \cdot 2$ ), or cells fixed with $4 \%$ formalin were stained with haematoxylin and eosin.

\section{ANTIBODY TO RHEUMATOID SYNOVIAL}

COLLAGENASE

Sheep antibody to purified rheumatoid synovial collagenase was shown to be pure and specific as judged by double diffusion, immunoelectrophoretic, and enzyme adsorption techniques (Woolley et al., 1976, 1977). For immunohistochemical studies specific IgG antibody was separated from other immunoglobulins by affinity chromatography on a collagenase-Sepharose 4B column using $50 \mathrm{mM}$ sodium citrate buffer, $\mathrm{pH} 3 \cdot 8$, to dissociate the antigen : antibody complex. The purified immune IgG was dialysed against phosphate-buffered saline (PBS) containing $0.05 \%$ sodium azide as preservative.

Double diffusion in agarose gels $(1 \%, \mathrm{w} / \mathrm{v})$ containing $50 \mathrm{mM}$ Tris-HCl buffer, $\mathrm{pH} 8 \cdot 0,0 \cdot 17 \mathrm{M}$ $\mathrm{NaCl}$ and $10 \mathrm{mM} \mathrm{CaCl}$, using antibody dialysed against the same buffer, was carried out as described previously (Woolley et al., 1977).

\section{COLLAGENASE IMMUNOHISTOCHEMISTRY}

For immunohistochemical studies on adherent synovial cells collagen-coated coverslips were fixed at vatious times of culture by immersion in $80 \%$ ethanol for $30 \mathrm{~s}$ and air-dried. After washing in phosphate buffered saline (PBS) the cells were treated with the collagenase antibody (sheep antihuman collagenase immunoglobulins, $100 \mu \mathrm{g} / \mathrm{ml}$ PBS) for $45 \mathrm{~min}$ at room temperature and washed for $1 \mathrm{~h}$ with 3 changes of PBS. FITC-labelled rabbit antisheep IgG (Wellcome Reagents) was then added for $30 \mathrm{~min}$ at $60: 1$ PBS dilution. The coverslips were then washed for $1 \mathrm{~h}$ in the dark with 3 changes of PBS, mounted with glycerine/PBS, and examined immediately with a Zeiss Photomicroscope III fitted with epifluorescent illumination. Fluorescence micrographs were made with Kodak High Speed Ektachrome ASA125 film with developing uprated to ASA250.

All studies on collagenase immunolocalisation were accompanied by controls containing nonimmune sheep IgG $(200 \mu \mathrm{g} / \mathrm{ml})$ in place of the antibody and the FITC-conjugated antibody reagent alone at a 60:1 dilution. No nonspecific FITC staining was observed with these controls. Similarly, controls with blocking antisera (unlabelled rabbit antisheep IgG antibody) applied after exposing the cells to the collagenase antibody were also negative. Moreover, when the antibody IgG was absorbed by incubation with excess purified collagenase for $1 \mathrm{~h}$ at $22^{\circ} \mathrm{C}$ no positive FITC-fluorescence was subsequently observed with cells which demonstrated positive fluoresence with untreated collagenase antibody.

Counterstaining of the cells with eriochrome black was often used to stain the whole cell cj toplasm orange-red and ethidium bromide was used to specifically counterstain the cell nuclei (Poole et al., 1973). 
Unfixed cryostat sections $(8 \mu \mathrm{m})$ of rheumatoid synovial tissue were treated with equivalent amounts (100 $\mu \mathrm{l}$ of 1050 units $/ \mathrm{ml} ; 1$ unit degrades $1 \mu \mathrm{g}$ collagen fibrils $/ \mathrm{min}$ at $37^{\circ} \mathrm{C}$ ) of latent and trypsinactivated enzyme for $5 \mathrm{~h}$ and $10 \mathrm{~min}$ respectively at $37^{\circ} \mathrm{C}$ in DMEM. The sections were then washed for $30 \mathrm{~min}$ with DMEM at room temperature $\left(22^{\circ} \mathrm{C}\right)$ and fixed with $80 \%$ ethanol and examined with the FITC-antibody technique.

\section{SCANNING ELECTRON MICROSCOPY}

Collagen-coated coverslips with adherent synovial cells were fixed in $2 \%$ glutaraldehyde (Electron Microscopy Sciences, Fort Washington, PA) buffered in $0.1 \mathrm{M}$ HEPES (Sigma Chemical Corp.) at $\mathrm{pH} 6.7$ for $45 \mathrm{~min}$ at room temperature. After 3 washes in the fixative the coverslips were immersed in $1 \%$ osmium tetroxide (Ladd Research Industries, Inc., Burlington) for $2 \mathrm{~h}$ on ice in a fume hood. After 3 rinses in HEPES the coverslips were dehydrated in successive baths of $30 \%, 75 \%, 95 \%$, and $100 \%$ ethyl alcohol at room temperature. Samples were then dried in a critical point drying apparatus with liquid $\mathrm{CO}_{2}$ and mounted on aluminium stubs (Ladd Research Industries, Inc.) with silver conducting paint (Ted Pella Co., Tuscin, California). A $10 \AA(1 \mathrm{~nm})$ thickness of gold was sputter-coated on to each specimen. Samples were viewed in a Coates and Welter Instrument Corporation Model 102 Field Emission Scanning Electron Microscope.

\section{COLLAGENASE ASSAYS}

${ }^{14} \mathrm{C}$-labelled guinea-pig skin collagen $(6000 \mathrm{dpm}$ per $\mathrm{mg}$ ) was purified from neutral salt or $0.5 \mathrm{M}$ acetic acid extracts as previously described (Werb et al., 1977). Culture medium harvested from the cell cultures was assayed for both spontaneously active and latent collagenase. The latter was activated in vitro by exposure to trypsin (TPCK Sigma, $10 \mu \mathrm{g}$ per $\mathrm{ml}$ for $30 \mathrm{~min}$ at $25^{\circ} \mathrm{C}$ ) with subsequent addition of a fourfold excess of soybean trypsin inhibitor (Sigma). The assay conditions for the ${ }^{14} \mathrm{C}$-labelled reconstituted collagen gel were those described previously (Werb et al., 1977).

\section{Results}

\section{MORPHOLOGY AND HISTOCHEMISTRY}

Approximately $50 \%$ of dissociated rheumatoid synovial cells adhere to glass or plastic surfaces when cultured for $24 \mathrm{~h}$ at $37^{\circ} \mathrm{C}$ in DMEM plus $10 \%$ fetal calf serum. Nonadherent cells such as lymphocytes, red cells, and polymorphonuclear leucocytes were removed from the culture by gentle washing after $24 \mathrm{~h}$ with HBSS followed by DMEM plus $0 \cdot 2 \%$ lactalbumin hydrolysate. The adherent cells com- prised 3 principal morphological types described a: fibroblast-like, macrophage-like, and dendritic. The fibroblast-like cells make up the bulk of the ce磨 population and appear usually as elongated cells occasionally with several spiky cytoplasmic pro cesses, and often containing phase-dense cytoplasmi $\overline{\bar{\alpha}}$ granules and vesicles in a perinuclear region. Th. macrophage-likecells are usually rounded and appeahิ flattened with ruffled edges and have a large cyto $\cong$ plasm/nucleus ratio. These cells constitute only $\vec{P}$ small percentage of most dissociated adherent rheumatoid synovial cell populations. The thirw type of cell is clearly recognised by its multi branched cytoplasmic processes and has been des cribed as a 'stellate' or 'dendritic' cell (Dayer et al. 1976; Werb et al., 1977).

Fig 1a is a phase-contrast micrograph which illustrates these 3 types of synovial cell. The proo portion of dendritic cells in adherent cell cultures varied with each tissue specimen, from as few as $2 \%$ to as many as $40 \%$, but usually representec approximately $10 \%$ of the total cell population. No significant change in the proportions of the cell types was observed during the first 5 days of culture, and as there was no change in cell density (owing to the lack of cell division in serum-frees culture medium) it would appear that cells were not undergoing morphological transformations once̋ they had adhered to a glass, plastic, or collagen substratum.

Various forms of the dendritic cell were observect as illustrated in Fig. 1b. Most were characterisedby long, branched cytoplasmic processes, varyingo in number from 2 or 3 to many (for example, I and Iho of Fig. 1b). Usually all had flattened, ruffled $\overline{2}$ terminal extensions to the dendritic processes. Most of the dendritic cells observed were mono- of binucleate, with each oval-shaped nucleus usually containing at least 2 prominent nucleoli. Occasion- 2 ally multinucleated dendritic cells were observed.은 In addition to the dendritic cells having compact cytoplasm around the nuclei, the cytoplasmic processes often showed bulbous protrusions wheres the plasma membrane was displaced by large, rounded inclusions. On vital staining with Janus green some inclusions were positively stained, $\omega$ suggesting that they are mitochondria (Fig. 1c), In contrast, the fibroblast- and macrophage-like cells revealed only a few Janus green-positive in-क clusions. When the cell cultures were incubated with ${ }^{+}$ latex particles for 24 or $48 \mathrm{~h}$ there was no evidence $\frac{T}{T}$ of phagocytosis by the dendritic cells. Vital staining $\underset{\mathbb{C}}{\vec{C}}$ with acridine orange to detect lysosomal structures? showed their presence in all cell types. Lysosomes $\varrho$ of the dendritic cells were of much the same size as

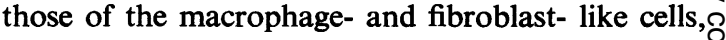




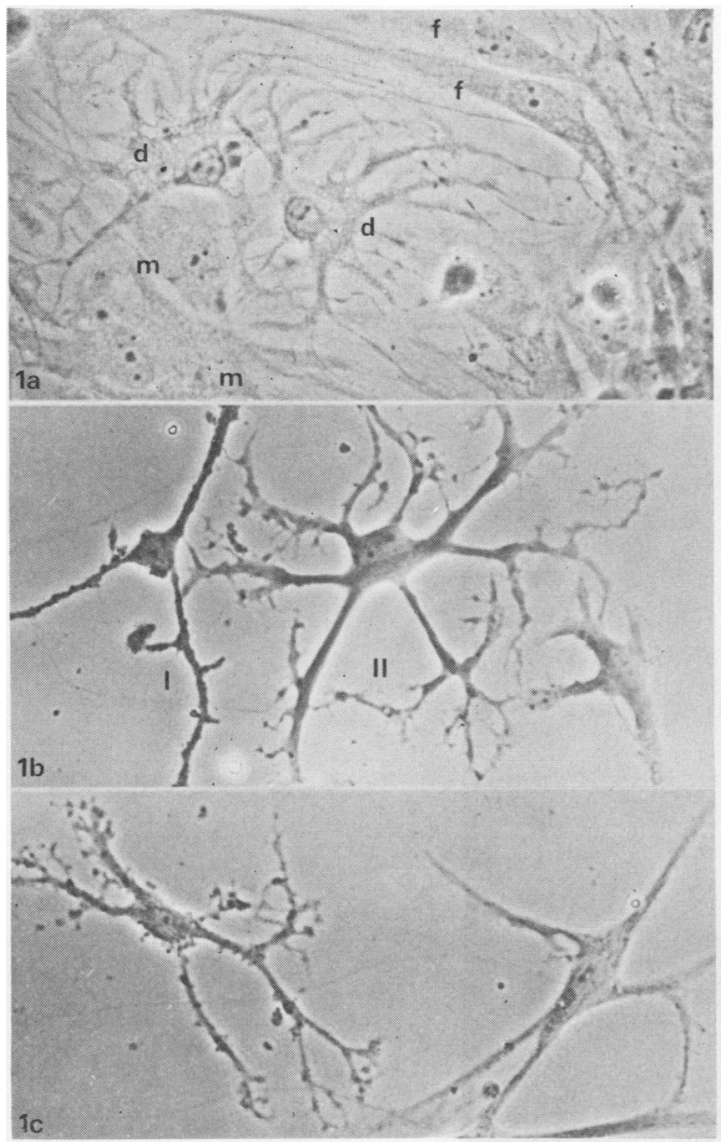

Fig. 1 Morphology of dissociated, adherent rheumatoid synovial cells. 1a. Phase-contrast micrograph of the mixed cell population comprising fibroblast-like (f), macrophage-like $(\mathrm{m})$, and dendritic cells $(\mathrm{d}) . \times 500$.

1b. Two examples of dendritic cells stained with toluidine blue showing the long branched cytoplasmic processes and compact cytoplasm around the nuclei.

$\times 1000$. 1c. Phase-contrast micrograph of cells exposed to Janus green. The dendritic cell contains many positively-stained inclusions. $\times 1000$

but were much smaller than the rounded inclusions which distorted the plasma membrane of the extensions.

\section{COLLAGENASE IMMUNOLOCALISATION}

\section{ST UDIES}

When cultured in DMEM plus $0 \cdot 2 \%$ lactalbumin hydrolysate the adherent rheumatoid synovial cells produced collagenase in both active and latent forms (Werb et al., 1977). In an attempt to determine which of the 3 cell types was responsible for enzyme production the cells were cultured on collagen-coated coverslips in DMEM. After 2, 3, or 4 days cultures were fixed in $80 \%$ ethanol and the immunolocalisation of collagenase was examined by the indirect or sandwich technique. Fig. 2a shows a phase-contrast micrograph of a mixed population of cells after 3 days in culture. When this cell culture was subjected to antibody treatment, positive FITC fluorescence was observed only with the dendritic cells (Figs. 2b and 2c), suggesting that these cells are responsible for collagenase production at this stage of culture. Fluorescence was clearly associated with the dendritic extensions and the perinuclear region.

As shown in Fig. 3a, in any 1 culture not all dendritic cells showed immunofluorescence at the same time. Here 1 dendritic cell is intensely fluorescent

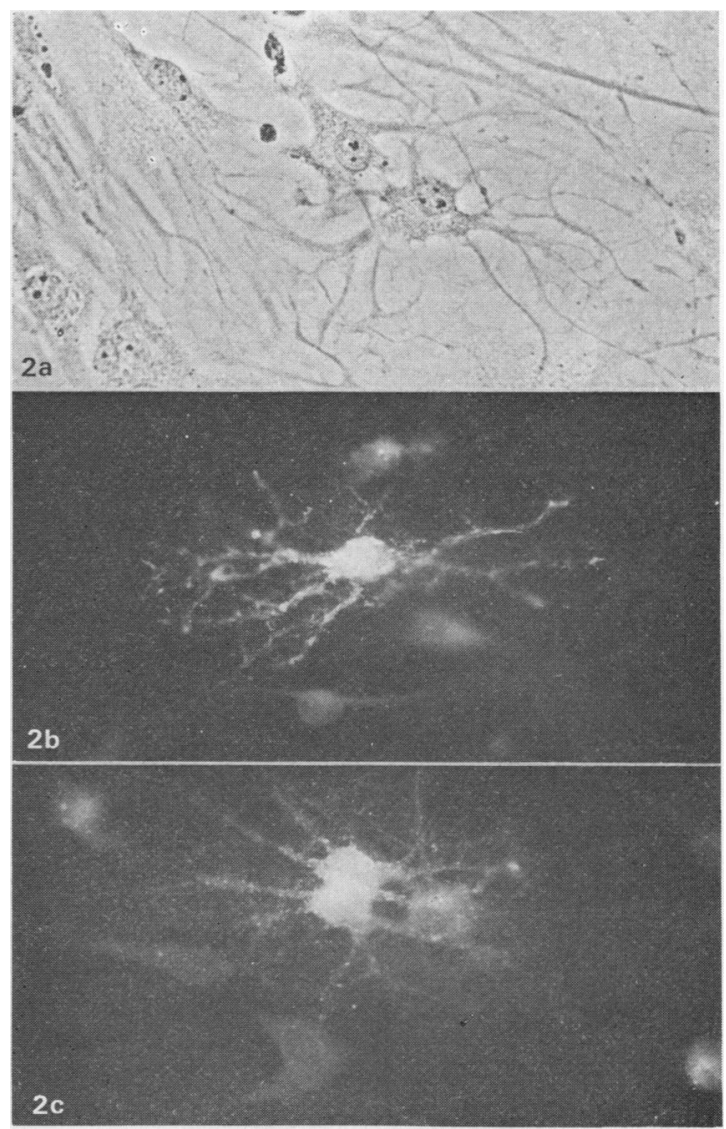

Fig. 2 Collagenase immunolocalisation studies of the synovial dendritic cells adherent to collagen-coated coverslips. 2a. Phase-contrast micrograph illustrating the mixed-cell population used in the immunofluorescent studies shown in $2 \mathrm{~b}$ and $2 \mathrm{c}$. Note that the FITCfluorescence is restricted to cytoplasmic extensions which clearly indicate the morphology of a mono- and binucleate dendritic cell respectively. No positive fluorescence is seen with surrounding cells. $\times 500$ 
whereas an adjacent similar cell is not. Two more examples of dendritic cells yielding positive FITCfluorescence are shown in Figs. 3b and 3c. These are both binucleate cells, fixed on day 4 of culture, showing extracellular as well as intracellular fluorescence. When fluorescence was occasionally seen with fibroblast- and macrophage-like cells it was always localised to the intracellular, perinuclear region (Figs. 3d, 3e, 3f).
When the same cell culture was plated on to glass coverslips not coated with collagen, the FITC: fluorescence of the cells was considerably reduces and limited to the perinuclear region. It thus seem likely that the more extensive fluorescence seen whe these cells were cultivated on collagen gels represents extracellular enzyme bound by its substrate afte\& release. Support for this interpretation was obtainegु by the observation of fluorescence which took the

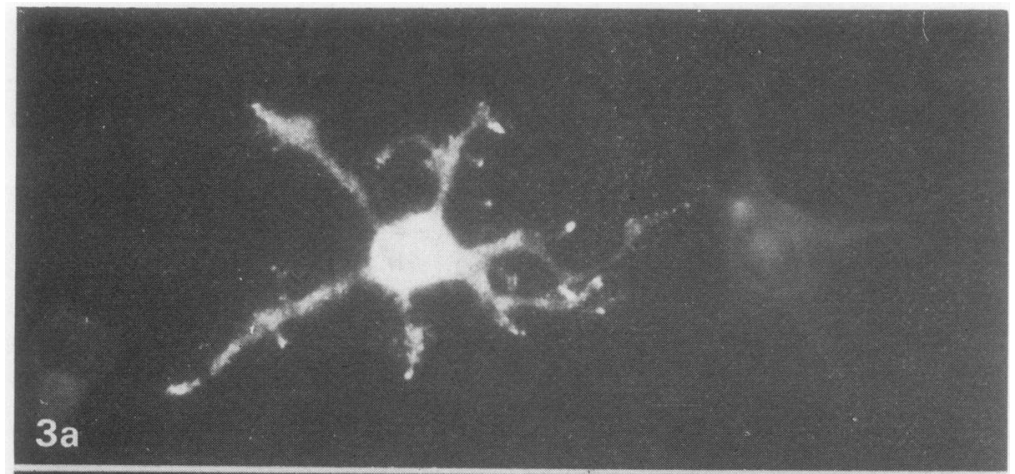

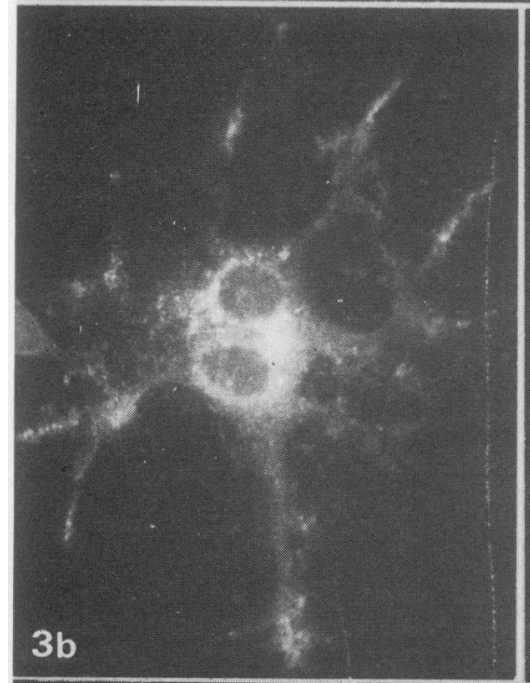
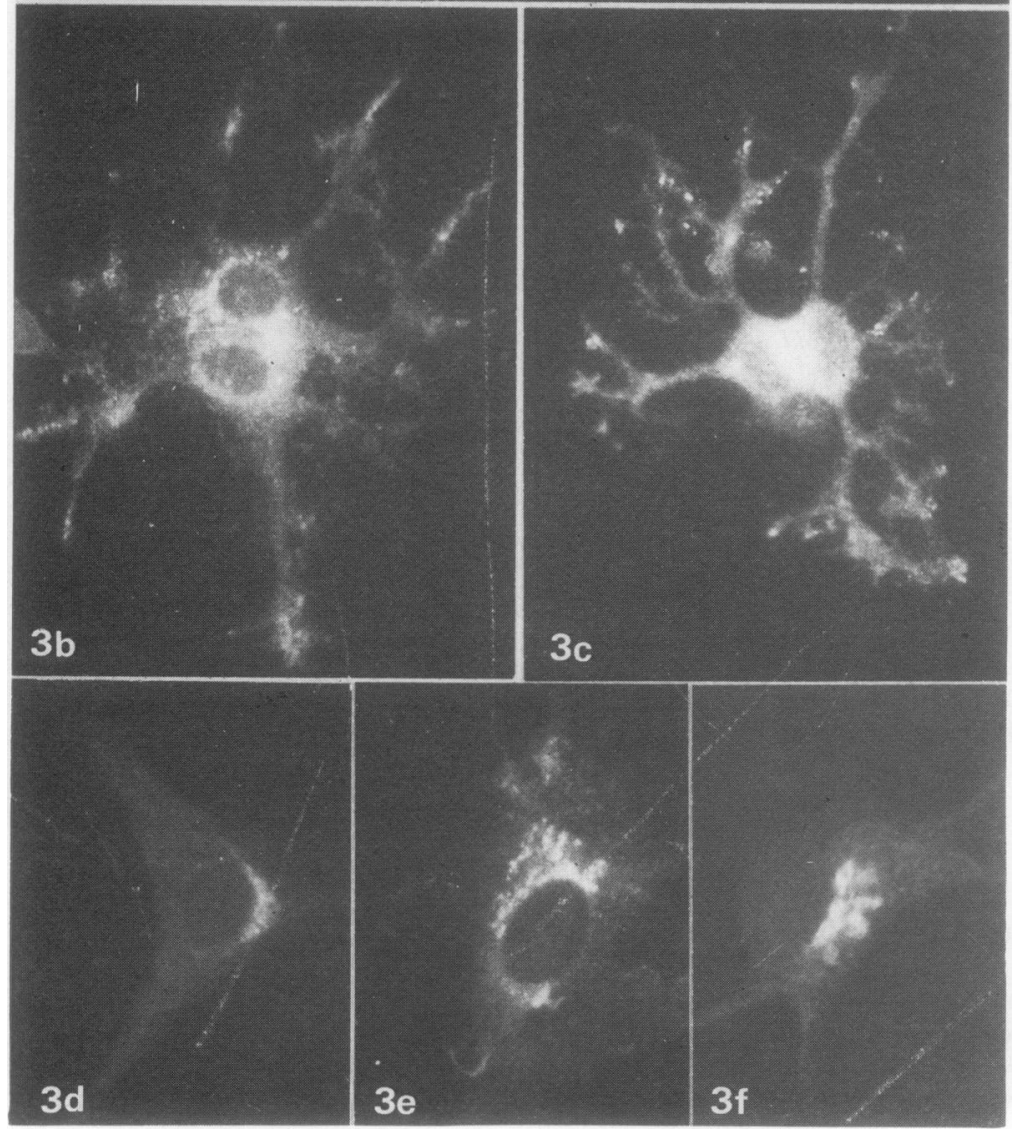

Fig. 3 Collagenase immunofluorescence of adherent rheumatoid synovial cells. $3 \mathrm{a}$. 3b. and 3c. FITC-fluorescence associated with dendritic cells after 4 days in culture. $\times 960$. 3d. 3e, and 3f. FITC-fluorescence confined to a perinuclear, intracellular location in fibroblast-like cells (3d. 3f) and macrophage-like cells (3e). $\times 1440$. 
form of 'footprints' of dendritic cells which had apparently been detached prior to antibody treatment (Fig. 4a). More conclusive evidence for extracellular enzyme is presented in Fig. 4b, which shows a dendritic cell with punctate FITC deposits of collagen-bound collagenase radiating from the cell, but from which the dendritic processes have either been withdrawn or displaced laterally. This photograph clearly illustrated the association of the extensions (arrowed and counterstained with eriochrome black) with the tracks of extracellular, collagen-bound enzyme.

Since the synovial cell cultures produced both active and latent forms of collagenase and predominantly the latter at the early stages of culture (Werb et al., 1977) it was important to determine what form of enzyme was being detected by the antibody. Double diffusion studies were used to assess immunoreactivity of the antibody with concentrated latent collagenase, activated latent enzyme, and an equivalent amount of active enzyme derived from primary cultures of synovial explants (Woolley et al., 1975b). Six latent enzyme preparations were examined, and 4 produced a precipitin response with the antibody. However, when activated by trypsinisation, latent enzyme preparations produced an increased precipitin response showing a reaction of identity with that produced by an equivalent amount of active enzyme from culture medium of synovial explants (Fig. 5). This finding suggests that the latent collagenase is itself weakly immunoreactive but that the activation process clearly unmasks more antigenic sites. However, as latent enzyme preparations may contain some denatured collagenase, or may undergo some degree of autoactivation (for example, Stricklin et al., 1977) during immunodiffusion, the immunoreactivity of latent synovial collagenase remains uncertain. It is known that enzyme rendered inactive by complexing with the serum inhibitors $\alpha_{2}$-macroglobulin or $\beta_{1}$-anticollagenase does not react with antibody in double diffusion experiments (Woolley et al., 1976, and 1977).

Further studies using the immunolocalisation technique to detect latent and active enzyme are illustrated in Fig. 6. Here frozen sections of unfixed rheumatoid synovial tissue, previously shown to have no immunofluorescent reaction, were exposed to equivalent amounts of latent and trypsin-activated collagenase. After fixation in $80 \%$ ethanol the sections were subjected to the fluorescent antibody technique. Intense FITC-fluorescence was observed in those sections exposed to active enzyme (Fig. 6a), whereas those exposed to latent enzyme showed relatively little FITC-fluorescence.

\section{SCANNING ELECTRON MICROSCOPY}

The unusual morphology of the dendritic cell with its cytoplasmic inclusions and the collagenase immunolocalisation studies prompted further morphological examination of this cell type. Accordingly scanning electron microscopy was carried out, and in Fig. 7a a dendritic cell extended on a collagen film is shown with many spherical inclusions projecting prominently from the dendritic extensions of the cell. The flattened, ruffled terminal extension of each dendritic process is also illustrated. The spherical inclusions often give a 'knobbly' appearance varying in size, and sometimes packing the process along the whole length (Fig. 7b). The long thin cell process

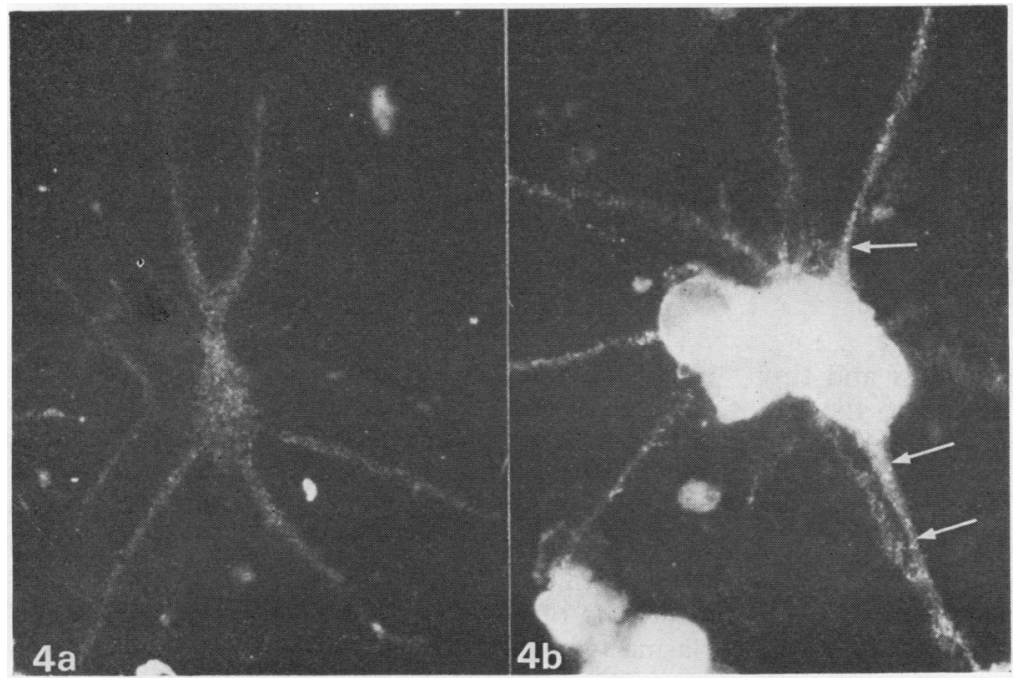

Fig. 4 Detection of extracellular collagenase in rheumatoid synovial cell cultures. 4a. A 'footprint' of positive FITC-fluorescence on a collagencoated coverslip indicates the outline of a dendritic cell, which was presumably secreting collagenase prior to detachment. 4b FITC-tracks of extracellular collagenase radiating from a cell counterstained with eriochrome black. Only 2 cytoplasmic extensions are observed and these are arrowed. $\times 1440$. 
with their broadened terminal extensions and tiny microprocesses which appear to adhere to the collagen fibrils clearly indicate a large surface area.

\section{Discussion}

This paper has described our examination in detail of some features of the dendritic cells observed in monolayer cultures of isolated rheumatoid synovial
Fig. 5 Immunodiffusion of the specific antibody to rheumatoid synovial collagenase against the latent and activated forms of enzyme obtained from cell cultures. Equivalent amounts of latent enzyme, trypsin-activated enzyme and active enzyme obtained from serum-free tissue culture of explanted rheumatoid synovium, were run against the sheep antibody (Ab, $20 \mathrm{mg} \mathrm{IgG/}$ $\mathrm{ml})$. Two latent enzyme preparations $\left(\mathrm{E}_{\mathrm{L}} 1\right.$ and $\left.\mathrm{E}_{\mathrm{L}} 2\right)$ are compared with equivalent amounts of active enzyme in A (20 units) and $\mathrm{B}(30$ units). The immunoreactivity of the latent form of collagenase was markedly weaker than that of the active forms. $\mathrm{E}^{\prime} 1$ and $\mathrm{E}^{\prime}$, trypsin-activated latent enzyme; $\mathrm{E}_{\mathrm{EXP}}$ active enzyme from cultured explants

Fig. 6 FITC-immunofluorescence of rheumatoid synovial tissue sections after exposure to either latent or trypsin-activated collagenase. Frozen tissue sections were exposed to equivalent amounts of active and latent enzyme and examined as described in 'Materials and methods'. Treatment with active enzyme was followed by intense FITC-fluorescence (6a), whereas prior exposure to latent enzyme gave very weak fluorescence (6c) when compared with the control tissue section without enzyme (6b). $\times 480$ cells adhering to and spreading on glass, plastic, or collagen substratum. The cells are characterised as having relatively large single or double refractile nuclei surrounded by compact cytoplasm and longbranched cytoplasmic processes. The extensions often contain large spherical or ovoid inclusions as $\frac{\text { के }}{\mathbb{8}}$ well as mitochondria and lysosomes. The largee inclusions often modify the smooth outline of the plasma membrane into bulbous excrescences, 


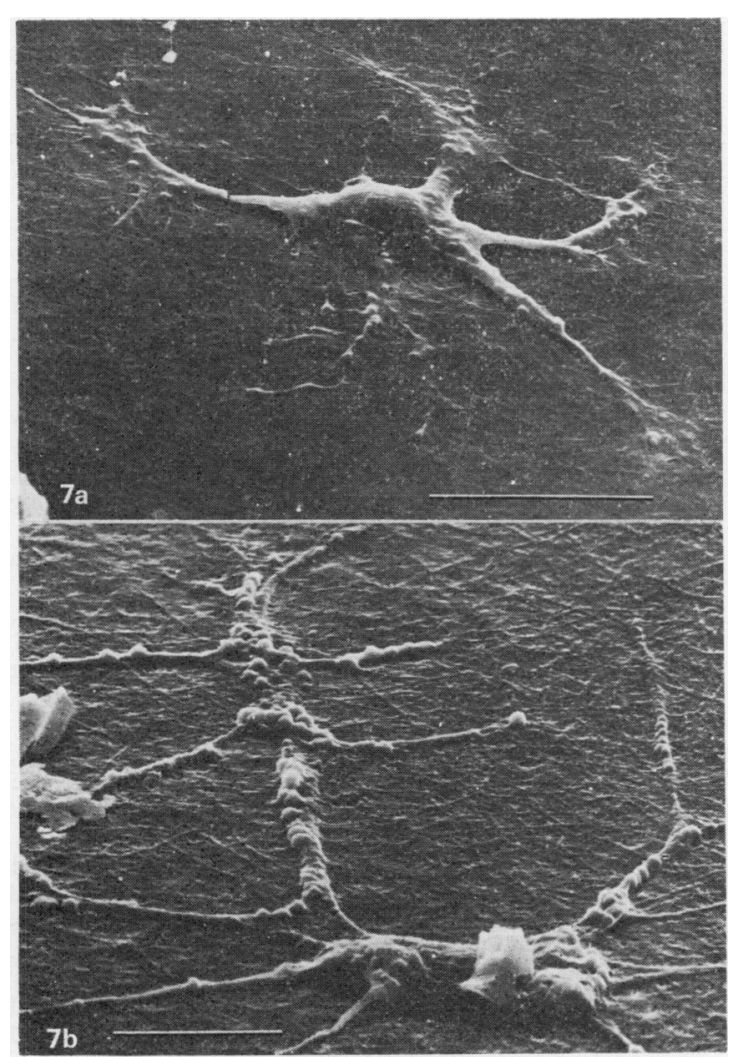

Fig. 7 Scanning electron micrographs of cultured dendritic rheumatoid synovial cells extended on a collagen substratum. Note the flattened terminal extensions with fine microprocesses of the cell illustrated in 7a. Bar, $20 \mu \mathrm{m}$, Both cells have the characteristic spherical inclusions which distort the plasma membrane giving a 'knobbly' appearance seen particularly well in $7 \mathrm{~b}$. Bar, $10 \mu \mathrm{m}$.

appearing as 'knobbly' processes when observed with scanning electron microscopy.

It is important to emphasise that within our classification of 'dendritic cells' there appeared to be heterogeneity in both a morphological and functional sense. Cell shapes varied, and the different distributions of cellular inclusions suggest that we may be looking either at several species of the same cell or at a cell type which is capable of morphological changes which might be correlated with different biological activities. In any single culture, as judged by immunofluorescence, not all the dendritic cells were producing collagenase at the same time, even though all were presumably subject to the same environmental conditions. So far we have no information on the time course of collagenase production by individual cells throughout the culture period, and we cannot exclude the possibility that there is a subpopulation of collagenase-producing dendritic cells.

The immunohistochemical study showed that the dendritic cells were those largely responsible for collagenase production in monolayer cultures, and a preliminary account of these observations has been reported (Woolley et al., 1978). Our findings from immunodiffusion and immunofluorescent studies of both active and latent enzyme preparations suggest that most of the positive FITC- fluorescence represents active enzyme which is collagen-bound. This is also supported by our observations of little or no fluorescence during the first 2 days of culturewhen only latent enzyme is found in the culture medium. As active enzyme begins to appear in the culture, this is paralleled by an increase in the amount of positive immunofluorescence.

Our interest in the dendritic cells in rheumatoid synovial cell cultures grew from our observations, stimulated by the studies of Dayer et al. (1976), that the dendritic cells found in adherent cell populations after enzymatic dissociation could not be seen growing out from primary explants of rheumatoid synovial tissue. Either they represent a unique cell type or they have assumed this appearance in response to some step in the preparative technique, for example, the collagenase/trypsin treatment during the process of dissociation. Alternatively, the dendritic morphology may result from the influence of inflammatory mediators on certain cells, possibly in a manner analogous to the morphological transformation of cultured bone cells exposed to humoral influences such as hormones and cyclic nucleotides (Miller et al., 1976). The observation that the proportion of dendritic cells in each culture did not change significantly during the first 5 days of culture suggests that this cell is probably not undergoing a sequential morphological transformation similar to that described for cultured macrophages of rheumatoid synovial fluids (Mackay et al., 1974).

The dendritic cells are morphologically similar to those reported in mouse spleen cell cultures by Steinman and Cohn (1973), who also described many mitochondrial structures within the cytoplasmic extensions of the cells. However, a functional characterisation of these cells is not available. Transformation of cultured bone cells to a stellate form by hormones, purine nucleosides/nucleotides, and cytochalasin B has been achieved in vitro (Miller et al., 1976), but again nothing is known about the biochemical function of this altered cell. Similarly, the possible relationship of the synovial dendritic cell to reticuloendothelial cells of similar appearance is uncertain for reasons detailed by 
Steinman and Cohn (1973) for their mouse spleen dendritic cells.

As collagenase has been shown to have an important role in cartilage destruction in the rheumatoid joint (Harris and McCroskery, 1974; Krane, 1975; Woolley and Evanson, 1977) further studies on the distribution and physiology of the dendritic cell, especially with regard to the effects of intermediates of chronic inflammation such as lymphokines (Dayer et al., 1977a) and prostaglandins (Dayer et al., 1977b) on morphology and enzyme production would hopefully improve our understanding of the role of this cell in the rheumatoid lesion.

This work was supported by grants from the Nuffield Foundation and Arthritis and Rheumatism Council, UK, by USPHS Grant AMI4780 and by a Clinical Research Center Grant from the Arthritis Foundation. We thank Dr K. Merritt and the Department of Surgery, Dartmouth-Hitchcock Medical Center, for use of a Zeiss Photomicroscope III with phase and epi-illumination, and the New Hampshire Chapter of the Arthritis Foundation which sponsored Dr Woolley's visit to Dartmouth.

We gratefully acknowledge help of Drs T. B. Roos and David Burgess, Department of Biology, Dartmouth College, for use of the scanning electron microscope and for instruction in preparation of specimens for examination.

\section{References}

Dayer, J. M., Krane, S. M., Russell, R. G. G., and Robinson, D. R. (1976). Production of collagenase and prostaglandins by isolated adherent rheumatoid synovial cells. Proceedings of the National Academy of Science of the USA, 73, 945-949.

Dayer, J. M., Russell, R. G. G., and Krane, S. M. (1977a). Collagenase production by rheumatoid synovial cells: stimulation by a human lymphocyte factor. Science, 195, 181-183.

Dayer, J. M., Robinson, D. R., and Krane, S. M. (1977b). Prostaglandin production by rheumatoid synovial cells: stimulation by a factor from human mononuclear cells. Journal of Experimental Medicine, 145, 1399-1407.

Evanson, J. M., Jeffrey, J. J., and Krane, S. M. (1968). Studies on collagenase from rheumatoid synovium in tissue culture. Journal of Clinical Investigation, 47, 2639-2651.
Harris, E. D., Jr., and McCroskery, P. A. (1974). Tḥ̆e influence of temperature and fibril stability on degradation of cartilage collagen by rheumatoid synovial collagenase. New England Journal of Medicine, 290, 1-6.

Krane, S. M. (1975). Collagenase production by hum synovial tissues. Annals of the New York Academy of Sciences, 256, 289-303.

Mackay, J. M. K., Panayi, G., Neill, W. A., Robinson, Smith, W., Marmion, B. P., and Duthie, J. J. R. (1974). Cytology of rheumatoid synovial cells in culture. Composition and sequence of cell populations in cultures of rheumatoid synovial fluids. Annals of Rheumatic Diseases, 33, 225-233.

Miller, J. M. K., Wolf, G. A. M., and Arnaud, C. D. (197 Bone cells in culture: morphologic transformation hormones. Science, 192, 1340-1342.

Poole, A. R., Hembry, R. M., and Dingle, J. T. (19732 Extracellular localization of cathepsin $\mathbf{D}$ in ossifyiff cartilage. Calcified Tissue Research, 12, 313-319.

Steinman, R. M., and Cohn, Z. A. (1973). Identification off novel cell type in peripheral lymphoid organs of mide? Journal of Experimental Medicine, 137, 1142-1151.

Stricklin, G. P., Bauer, E. A., Jeffrey, J. J., and Eisen, A. Z (1977). Human skin collagenase: Isolation of precurser and active forms from both fibroblast and organ cultures. Biochemistry, 16, 1607-1615.

Werb, Z., Mainardi, C. I., Vater, C. A., and Harris, E. DJr. (1977). Endogenous activation of latent collagenase by rheumatoid synovial cells. New England Journal \& Medicine, 296, 1017-1023.

Woolley, D. E., Lindberg, K. A., Glanville, R. W., ane Evanson, J. M. (1975a). Action of rheumatoid synovi collagenase on cartilage collagen. Different susceptibiliti of cartilage and tendon collagen to clolagenase attacR. European Journal of Biochemistry, 50, 437-444.

Woolley, D. E., Glanville, R. W., Crossley, M. J., and Evanson, J. M. (1975b). Purification of rheumato synovial collagenase and its action on soluble and insolub collagen. European Journal of Biochemistry, 54, 611-62z

Woolley, D. E., Crossley, M. J., and Evanson, J. M. (1978 Antibody to rheumatoid synovial collagenase. Its chare acterization, specificity and immunological cross-reactivity European Journal of Biochemistry, 69, 421-428.

Woolley, D. E., Crossley, M. J., and Evanson, J. M. (197 Collagenase at sites of cartilage erosion in the rheumato joint. Arthritis and Rheumatism, 20, 1231-1239.

Woolley, D. E., and Evanson, J. M. (1977). Collagenase and its natural inhibitors in relation to the rheumator joint. Connective Tissue Research, 5, 31-36.

Woolley, D. E., Harris, E. D., Jr., Mainardi, C. L., and Brinckerhoff, C. E. (1978). Collagenase immunolocato zation in cultures of rheumatoid synovial cells. Science, 200, 773-775. 